\title{
Meta-Analysis of the Association Between a Serotonin Transporter Promoter Polymorphism (5-HTTLPR) and Anxiety-Related Personality Traits
}

\author{
Srijan Sen, ${ }^{1 *}$ Margit Burmeister, ${ }^{1,2}$ and Debashis Ghosh ${ }^{3}$ \\ ${ }^{1}$ Neuroscience Program, University of Michigan, Ann Arbor, Michigan \\ ${ }^{2}$ Mental Health Research Institute, Departments of Psychiatry and Human Genetics, University of Michigan, Ann Arbor, Michigan \\ ${ }^{3}$ Department of Biostatistics, University of Michigan, Ann Arbor, Michigan
}

\begin{abstract}
Anxiety-related personality traits, such as NEO neuroticism and TCI/TPQ harm avoidance, have been shown to have significant genetic components. To date, however, no specific genetic variants that contribute to these traits have been conclusively identified. At least 26 studies have investigated a putative association between a functional serotonin transporter promoter polymorphism (5-HTTLPR) and anxiety-related personality traits. The results of these studies have been inconsistent with some studies finding evidence for an association, and others not. We performed a meta-analysis of all applicable studies investigating this association. In the overall analysis ( $N=\mathbf{5 , 6 2 9}$ subjects), we found suggestive evidence for an association between the 5-HTTLPR short allele (s) and increased anxiety-related personality trait scores $(P=0.087)$. However, we also found strong evidence for heterogeneity. This heterogeneity is largely explained by substantial variation between the studies in the inventory used. When the analysis was stratified by inventory type, there was a significant association between 5-HTTLPR and NEO neuroticism $(P=0.000016)$, a non-significant association between 5-HTTLPR and TCI/TPQ harm avoidance $(P=0.166)$, and no association between 5-HTTLPR and other anxiety-related personality traits $(P=0.944)$. There was no evidence that these results were either due to publication bias or accounted for by any one single study. We conclude that there is a strong association between the serotonin transporter promoter variant and neuroticism as measured in the NEO personality inventory and that non-replications are largely due to small sample size and the use of different inventories. (c) 2004 Wiley-Liss, Inc.
\end{abstract}

\author{
KEY WORDS: neuroticism; harm avoidance; \\ personality; variant; polymorph- \\ ism; depression
}

\section{INTRODUCTION}

Evidence from twin studies indicate that a substantial component of human personality trait variation is due to genetic factors [Loehlin, 1993]. Finding the specific genetic variants responsible for the personality trait variation however has proven difficult. A personality trait extensively studied in behavioral genetics is neuroticism. Neuroticism, as measured through the NEO personality inventories (NEO-PI-R, NEO-PI, and NEO-FFI), is characterized by "negative emotionality" such as anxiety, low mood, vulnerability, and hostility [Costa and McCrae, 1997].

Lesch et al. [1996] reported an association between a serotonin transporter promoter polymorphism (5-HTTLPR) and neuroticism. The serotonin transporter is located on the presynaptic membrane of serotonergic neurons and acts to resorb serotonin from the synapse. This protein is a target of the SSRI class of anti-depressant/anti-anxiety medications. 5-HTTLPR is a repeat polymorphism with two alleles, a 14 repeat (s) and 16 repeat (l), predominant in most population samples studies to date [Nakamura et al., 2000]. There is substantial evidence that the 1 allele is transcriptionally more active than the alternate s allele [Heils et al., 1995; Hanna et al., 1998].

Since the initial report of an association between 5-HTTLPR and neuroticism, there have been numerous attempts to replicate the finding. Some of these studies followed Lesch and colleagues and used NEO neuroticism as their phenotype [Ball et al., 1997; Nakamura et al., 1997; Gelernter et al., 1998; Deary et al., 1999; Flory et al., 1999; Kumakiri et al., 1999; Du et al., 2000; Greenberg et al., 2000; Sen et al. (in press); Stoltenberg et al., 2002; Umekage et al., 2003]. Another subset of studies investigated harm avoidance, a trait correlated with neuroticism measured by the temperament and character inventory (TCI)/tridimenstional personality questionnaire (TPQ) family of personality inventories [Ebstein et al., 1997; Mazzanti et al., 1998; Ricketts et al., 1998; Hamer et al., 1999; Katsuragi et al., 1999; Osher et al., 2000; Samochowiec et al., 2001; Tsai et al., 2002]. Harm avoidance is characterized by anxiety proneness and an aversion to risk taking [Zohar et al., 2003]. A third subset of studies employed other correlated but distinct traits as outcome measures [Jorm et al., 1998; Gustavsson et al., 1999; Murakami et al., 1999; Melke et al., 2001]. The results from these replication studies have been inconsistent. Seven replication studies found significant evidence for an association between the 5-HTTLPR $\mathrm{s}$ allele and higher anxiety-related personality trait scores while seventeen replication studies found no significant evidence of this association.
Grant sponsor: The Michigan Society of Fellows; Grant sponsor: Rachel Upjohn Clinical Scholars Program; Grant sponsor: NRSA; Grant number: MH64299-01A1.

*Correspondence to: Srijan Sen, MHRI c/o Burmeister Lab, 205 Zina Pitcher Place, Ann Arbor, MI 48109.

E-mail: srijan@umich.edu

Received 14 March 2003; Accepted 16 September 2003

DOI 10.1002/ajmg.b.20158

(c) 2004 Wiley-Liss, Inc. 
This inconsistency is typical for association studies involving complex traits [Hirschhorn et al., 2002]. One potential reason for discrepancies between studies investigating the same association is that with the sample sizes typically used in association studies, it is difficult to distinguish between genes that exert small effects on a complex trait and genes that exert no effect at all. The situation can be further complicated by variation between studies in both the population samples studied and the method used to evaluate the relevant trait. A technique that has proven useful in resolving discrepancies between association studies is meta-analysis [Lohmueller et al., 2003]. Meta-analysis is a quantitative method of combining the results of independent studies and synthesizing summaries and conclusions. This method increases power to distinguish between small effects and no effect. Furthermore, it can help determine whether variation in effect between studies is due merely to expected random statistical fluctuation, or also due to variation between studies in the sample used or trait assessment. Meta-analysis has been used successfully to both confirm [Altshuler et al., 2000; Faraone et al., 2001] and refute [Kluger et al., 2002; Lalovic and Turecki, 2002] putative associations between genetic variants and complex traits. In this study, we perform a meta-analysis on all available studies investigating the association between 5-HTTLPR and anxiety-related personality traits.

\section{MATERIALS AND METHODS}

\section{Studies}

Studies were identified through PubMed at the National Library of Medicine using the search terms: (1) neuroticism serotonin transporter, (2) harm avoidance serotonin transporter, (3) personality serotonin transporter. We subsequently checked the reference sections of the publications found through our search to identify additional studies that may have been missed. We restricted the scope of our analysis to studies that used adult samples. In total, 26 studies from 24 publications were identified, and 23 studies were included in the analysis (Table I). Three of these studies were excluded from our analysis because: (1) we were unable to obtain necessary information from the publication or the authors [Gelernter et al., 1998] or (2) the study design was incompatible with our analysis because only extreme values of neuroticism were genotyped [Ball et al., 1997; Deary et al., 1999].

\section{Statistical Analysis}

We recorded the number of subjects, mean anxiety-related personality trait score, and standard deviation for each of the three genotype groups $(\mathrm{s} / \mathrm{s}, \mathrm{s} / \mathrm{l}$, and $\mathrm{l} / \mathrm{l})$ in each study included in our analysis. We also recorded the inventory used in each study as well as the gender and ethnic compositions of the sample used in each study. Studies were grouped into three inventory categories: (1) NEO (NEO-PI, NEO-PI-R, and NEO-FFI), (2) TCI/TPQ (TCI and TPQ), and (3) others (EPQ, KSP, and SRQ$\mathrm{AD})$. For studies where all or part of this information was not available in the publication, the authors were contacted by email.

In order to have all studies on the same scale for our analysis, the raw score from each study-genotype group was converted to a T-score so that each study had an overall mean score of $50 \pm 10$. A random effects meta-analysis was performed with the study-genotype T-score as the dependent variable and genotype as the independent variable. Ethnicity and gender composition of the study were included as covariates and each study-genotype group was weighted according to the inverse of its variance. Three studies [Nakamura et al., 1997; Kumakiri et al., 1999; Osher et al., 2000] administered multiple inventories to the same sample. For these studies, the inventory for which more subjects had valid trait scores was used in the overall analysis. For analyses specific to one inventory, the studies using multiple inventories were included if the relevant inventory was used in the study regardless of whether the study used other inventories as well.

To ascertain if the results of our analysis were strongly influenced by any single study a sensitivity analysis was performed. Both the overall significance and the inventory specific significance of the analyses were recomputed after each study was individually deleted from the analysis (Table II).

In order to determine if there is a significant publication bias the method described by Egger et al. [1997] was used. This

TABLE I. Included Association Studies of 5-HTTLPR and Anxiety-Related Traits

\begin{tabular}{|c|c|c|c|c|c|c|}
\hline Study & Inventory & $\mathrm{N}$ & Mean age & Ethnicity & Female $(\%)^{\mathrm{a}}$ & Recruitment \\
\hline Jorm et al. [1998] & $\mathrm{EPQ}$ & 759 & 41.5 & 95\% Caucasian & 53 & Volunteer \\
\hline Hamer et al. [1999] & TCI & 634 & 31.3 & 79\% Caucasian & 57 & Volunteer \\
\hline Sen et al. (in press) & NEO-PI & 415 & 43.8 & Caucasian & 67 & Blood pressure \\
\hline Greenberg et al. [2000] & NEO-PI-R & 397 & 28.6 & $71 \%$ Caucasian & 84 & Volunteer \\
\hline Mazzanti et al. [1998] & $\mathrm{TPQ}$ & 397 & 35.5 & Caucasian & 15 & Alcoholic criminals \\
\hline Lesch et al. [1996] & NEO-PI & 284 & 37.6 & 94\% Caucasian & 8 & Homosexuality \\
\hline Umekage et al. [2003] & NEO-PI-R & 244 & 37.7 & Japanese & 100 & Volunteer \\
\hline Flory et al. [1999] & NEO-PI-R & 225 & 45.7 & $84 \%$ Caucasian & 50 & Community \\
\hline Lesch et al. [1996] & NEO-PI & 221 & 23.3 & $79 \%$ Caucasian & 7 & Volunteer \\
\hline Tsai et al. [2002] & $\mathrm{TPQ}$ & 192 & 29.3 & Chinese & 51 & Healthy \\
\hline Melke et al. [2001] & KSP & 190 & 42.0 & Caucasian & 100 & Volunteer \\
\hline Murakami et al. [1999] & SRQ-AD (Japanese) & 189 & 49.3 & Japanese & 38 & Volunteer \\
\hline Nakamura et al. [1997] & NEO-PI and TCI & 186 & 19.6 & Japanese & 100 & Students \\
\hline Du et al. [2000] & NEO-FFI & 186 & 36.3 & Caucasian & 59 & Volunteers \\
\hline Gustavsson et al. [1999] & KSP & 175 & 45.3 & Caucasian & 52 & Students \\
\hline Osher et al. [2000] & TPQ and NEO-PI-R & 148 & 30.7 & Caucasian & 66 & Students \\
\hline Kumakiri et al. [1999] & NEO and TCI & 144 & 24.4 & Japanese & 46 & Students \\
\hline Samochowiec et al. [2001] & TCI & 126 & 23.8 & Caucasian & 59 & Healthy \\
\hline Gustavsson et al. [1999] & KSP & 125 & 38.0 & Caucasian & 39 & Students \\
\hline Ebstein et al. [1997] & $\mathrm{TPQ}$ & 121 & 29.7 & Caucasian & 45 & Volunteer \\
\hline Katsuragi et al. [1999] & TPQ & 101 & 25.0 & Japanese & 39 & Students \\
\hline Stoltenberg et al. [2002] & NEO-FFI & 86 & 39.2 & Caucasian & 5 & Alcohol dependence \\
\hline Ricketts et al. [1998] & TPQ & 84 & 67.4 & Caucasian & 43 & Parkinsons disease \\
\hline
\end{tabular}

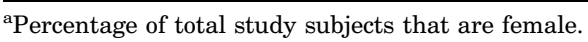


method regresses the standard normal deviate (estimated regression coefficient ( $\beta$ value) divided by standard error) against the weight (1/variance) of the study. In order to calculate the standard normal deviate, we first determined the $\beta$ value of each study by calculating the slope of the genotypeneuroticism regression line. This value corresponds to the effect on the T-score that results from the addition of one $\mathrm{s}$ allele. The $\beta$ values were also used to test for the presence of heterogeneity among the results of the studies. When evidence for heterogeneity was found, we determined the minimum number of studies that had to be removed to eliminate evidence of heterogeneity. All analyses were carried out in SPSS 10.0.07 (SPSS Inc., Chicago, IL).

\section{RESULTS}

Across all 23 included studies investigating 5-HTTLPR and anxiety-related personality traits $(\mathrm{N}=5,629)$, the weighted genotype T-scores were (mean $\pm \mathrm{SD}): \mathrm{s} / \mathrm{s}-52.13 \pm 9.72 ; \mathrm{s} / \mathrm{l}-$ $49.45 \pm 10.09 ; 1 / 1-48.98 \pm 10.11$. The meta-analysis showed suggestive evidence for an association between 5-HTTLPR and anxiety-related personality traits $(P=0.087)$. Neither the ethnic $(P=0.943)$ or gender $(P=0.763)$ composition of the studies were significant as covariates in the analysis. $\beta$ values indicate the change in T-score that results from the addition of one s allele. Across the studies, these values ranged from -1.47 to 21.93 with an overall $\beta$ value weighted mean of 1.68 (Table II). There was evidence for heterogeneity among the $\beta$ values of the studies $\left(\chi^{2}=472.3 ; \mathrm{df}=22 ; P<0.0001\right)$. To eliminate heterogeneity, the six studies contributing most strongly to the heterogeneity had to be removed from the analysis (Table III).

Given this significant heterogeneity, and the fact that gender and ethnic composition were not significant, we performed separate analyses for the three inventory categories. For the NEO category, there was a strong association between 5 -HTTLPR and neuroticism $(P=0.000016)$, while the TCI TPQ category studies showed a non-significant weak association between 5 -HTTLPR and harm avoidance $(P=0.166)$ and the other category showed no association between 5 HTTLPR and the anxiety-related personality traits $(P=0.944)$ (Table II). Among NEO studies, there was evidence of heterogeneity among the $\beta$ values $\left(\chi^{2}=28.7 ; \mathrm{df}=10\right.$; $P<0.0014)$. Removal of the one most extreme study eliminated the evidence for heterogeneity. For the TCI/TPQ category, there was also significant evidence for heterogeneity among the $\beta$ values $\left(\chi^{2}=400.6 ; \mathrm{df}=9 ; P<0.0001\right)$. Removal of six studies was necessary to eliminate the evidence for heterogeneity. For the category of other studies, significant evidence for heterogeneity among $\beta$ values also existed $\left(\chi^{2}=16.2 ; \mathrm{df}=4\right.$; $P<0.0028$ ). Removal of two studies was necessary to eliminate the evidence of heterogeneity (Table III).

To determine if an individual study was responsible for the presence or absence of an association in each of the tests, we performed a series of sensitivity analyses (Table II). Each study was individually excluded and the significance of the analysis was recomputed. In the analysis including all inventory categories, the significance of the association ranged from $P=0.037$ to $P=0.143$ after each study was individually excluded. For the NEO category, the significance ranged from $P=0.00000039$ to

TABLE II. Results and Sensitivity Analysis of 5-HTTLPR and Anxiety-Related Traits Association Studies

\begin{tabular}{|c|c|c|c|c|c|c|c|c|c|}
\hline Study & $\mathrm{N} \mathrm{s} / \mathrm{s}$ & $\mathrm{N} \mathrm{s} / \mathrm{l}$ & $\mathrm{N} \mathrm{l/1}$ & $\begin{array}{c}\text { T-score } \\
\mathrm{s} / \mathrm{s}^{\mathrm{b}}\end{array}$ & $\begin{array}{c}\text { T-score } \\
\mathrm{s} / \mathrm{l}^{\mathrm{b}}\end{array}$ & $\begin{array}{c}\text { T-score } \\
1 / 1^{b}\end{array}$ & $\beta$ value & $\begin{array}{c}\text { Exclusion } \\
P \text { value (all } \\
\text { studies) }^{c}\end{array}$ & $\begin{array}{c}\text { Exclusion } \\
P \text { value } \\
\text { (inventory) }^{\mathrm{d}}\end{array}$ \\
\hline Flory et al. & 37 & 112 & 76 & 47.11 & 50.92 & 50.04 & -1.47 & 0.071 & 0.00000039 \\
\hline Greenberg et al. & 66 & 217 & 114 & 50.13 & 51.13 & 47.76 & 1.19 & 0.105 & 0.00038 \\
\hline Kumakiri et al. & 85 & 48 & 11 & 49.94 & 50.16 & 49.76 & 0.09 & 0.091 & 0.000044 \\
\hline Lesch et al. $(23.3)^{\mathrm{a}}$ & 43 & 106 & 72 & 50.38 & 51.34 & 47.80 & 1.29 & 0.107 & 0.00018 \\
\hline Lesch et al. $(37.6)^{\mathrm{a}}$ & 52 & 141 & 91 & 51.22 & 50.68 & 48.25 & 1.49 & 0.111 & 0.00016 \\
\hline Nakamura et al. & 128 & 55 & 3 & 50.00 & 50.30 & 44.31 & 5.14 & 0.098 & 0.000058 \\
\hline Sen et al. & 83 & 183 & 149 & 52.15 & 50.50 & 48.19 & 1.98 & 0.139 & 0.00016 \\
\hline Stoltenberg et al. & 17 & 45 & 24 & 48.63 & 50.57 & 49.91 & -0.64 & 0.087 & 0.000020 \\
\hline Umekage et al. & 161 & 70 & 13 & 50.15 & 49.90 & 48.59 & 0.78 & 0.094 & 0.000052 \\
\hline Du et al. & 40 & 86 & 60 & 51.59 & 49.34 & 49.88 & 0.85 & 0.097 & 0.0000047 \\
\hline All NEO & 751 & 1133 & 648 & 50.31 & 50.64 & 48.51 & 1.06 & - & 0.000016 \\
\hline Tsai et al. & 100 & 71 & 21 & 49.98 & 50.12 & 49.69 & 0.15 & 0.090 & 0.138 \\
\hline Samachowiec et al. & 18 & 67 & 41 & 49.87 & 48.74 & 52.11 & -1.12 & 0.082 & 0.169 \\
\hline Ricketts et al. & 19 & 37 & 28 & 73.13 & 53.80 & 29.27 & 21.93 & 0.143 & 0.263 \\
\hline Osher et al. & 39 & 73 & 36 & 51.21 & 50.84 & 46.97 & 2.12 & 0.108 & 0.191 \\
\hline Mazzanti et al. & 76 & 196 & 125 & 50.92 & 49.90 & 49.60 & 0.66 & 0.095 & 0.217 \\
\hline Katsuragi et al. & 66 & 31 & 4 & 64.76 & 17.46 & 58.66 & 3.05 & 0.037 & 0.251 \\
\hline Hamer et al. & 108 & 336 & 190 & 50.26 & 50.69 & 48.64 & 0.81 & 0.099 & 0.127 \\
\hline Ebstein et al. & 32 & 66 & 23 & 56.98 & 45.36 & 53.61 & 1.68 & 0.107 & 0.230 \\
\hline All TCI/TPQ & 709 & $\mathbf{1 , 0 1 4}$ & 519 & 52.65 & 48.97 & 48.35 & 2.02 & - & 0.166 \\
\hline Gustavsson et al. $(45.3)^{\mathrm{a}}$ & 35 & 83 & 57 & 48.17 & 50.49 & 50.40 & -1.31 & 0.072 & 0.760 \\
\hline Gustavsson et al. $(38.0)^{\mathrm{a}}$ & 22 & 66 & 37 & 47.54 & 50.73 & 50.16 & -1.12 & 0.079 & 0.792 \\
\hline Jorm et al. & 155 & 350 & 254 & 49.76 & 50.15 & 49.94 & -0.09 & 0.064 & 0.810 \\
\hline Melke et al. & 35 & 84 & 71 & 53.56 & 48.58 & 49.92 & 1.82 & 0.104 & 0.953 \\
\hline Murakami et al. & 124 & 55 & 10 & 51.18 & 47.74 & 47.74 & 1.72 & 0.110 & 0.924 \\
\hline All other & 371 & 638 & 429 & 50.31 & 49.84 & 49.97 & 0.16 & - & 0.944 \\
\hline All studies & $\mathbf{1 , 3 3 1}$ & 2,432 & 1,461 & 52.13 & 49.45 & 48.98 & 1.68 & 0.087 & - \\
\hline
\end{tabular}

${ }^{a}$ Mean age provided in parentheses to differentiate between studies of different populations reported in the same publication.

${ }^{\mathrm{b}}$ Mean T-score for indicated genotype group.

${ }^{c}$ The overall significance when the study is excluded.

d The inventory specific significance when the study is excluded. 
TABLE III. Heterogeneity Among Beta Values for Inventory Categories

\begin{tabular}{lcccc}
\hline Inventory category & $\begin{array}{c}\text { Number of } \\
\text { studies }\end{array}$ & $\chi^{2}$ value & $P$ value & $\begin{array}{c}\text { Number of studies removed } \\
\text { to eliminate heterogeneity }\end{array}$ \\
\hline All studies & 23 & 472.3 & $<0.0001$ & 6 \\
NEO studies & 11 & 28.7 & 0.0014 & 1 \\
TCI/TPQ studies & 10 & 400.6 & $<0.0001$ & 6 \\
Other studies & 5 & 16.2 & 0.0028 & 2 \\
\hline
\end{tabular}

$P=0.00016$, indicating that no one study was individually responsible for the positive association. For the TCI/TPQ category, the significance ranged from $P=0.127$ to $P=0.263$, while for the other category, the significance ranged from $P=0.760$ to $P=0.953$ indicating that for both categories, no one study was responsible for the absence of an association. The publication bias statistic of Egger et al. was not significant $(P=0.515)$, suggesting that that there was no publication bias in the overall analysis.

\section{DISCUSSION}

This meta-analysis shows a borderline significant association between 5-HTTLPR and anxiety-related personality traits. In the overall analysis, there is strong evidence for heterogeneity among the $\beta$ values. Heterogeneity indicates that there is greater variation among the results of the studies than expected by chance. In general, this can result from variation among studies in a number of salient features including sample demographics and outcome measure. In the case of this meta-analysis, the heterogeneity seems to be due in part, to the different inventories used by the different studies. The two traits studied most frequently among studies included in this analysis are neuroticism, as measured by NEO inventories, and harm avoidance, as measured by TCI/TPQ inventories. These two traits have a correlation of 0.55 [De Fruyt et al., 2000], indicating that there is significant variation in the outcome measure between studies that used NEO inventories and studies that used TCI/TPQ inventories. On the other hand, the demographic variables included, gender and ethnic composition, were not significant as covariates in the analysis, indicating that they are unlikely to be major contributors to the heterogeneity found.

When the analysis is stratified by inventory type, there is a highly significant association between 5-HTTLPR and neuroticism among studies using NEO personality inventories. The sensitivity analysis indicates that this result is not unduly influenced by any one single study. Although heterogeneity persists among the NEO category studies, the evidence of heterogeneity is much weaker than for the analysis of all studies (all studies $\chi^{2}=472.3$, d.f $=22$; NEO studies $\chi^{2}=28.7$, d.f. $=10$ ). Furthermore, removal of one study from the analysis eliminates the evidence for heterogeneity, indicating that the heterogeneity among NEO studies is limited (Table III).

Among studies using TCI/TPQ inventories, the association between 5-HTTLPR and harm avoidance shows a trend in the same direction as NEO studies, but the result is nonsignificant. This non-significance is not the result of small overall sample size as the number of subjects in TCI/TPQ studies (2,242 subjects) is comparable to the number of subjects in NEO studies (2,532 subjects). Instead, the lack of significance seems to be due to the substantial heterogeneity between the results of these studies. Six of the ten studies had to be removed from the analysis to eliminate evidence for heterogeneity, indicating that the heterogeneity was not due to a small subset of the studies. The variation in results between the TCI/TPQ studies may be due in part, to the number of TCI/ TPQ studies using small samples (for $6 / 10$ studies, $\mathrm{N}<150$ ).
In addition, demographic variables not included in our analysis may have contributed to the heterogeneity among TCI/TPQ studies.

Among the studies using other inventories, there is no evidence of an association between 5-HTTLPR and anxietyrelated traits. In this category, significant evidence of heterogeneity among the results of these studies persists. Two of the five studies had to be removed to eliminate evidence for heterogeneity. These five studies used three different inventories: the Karolinska Scales of Personality [Gustavsson et al., 1999; Melke et al., 2001], the SRQ-AD [Murakami et al., 1999], and the Eysenck Personality Questionnaire-revised [Jorm et al., 1998]. It is likely that the residual heterogeneity in this category is due to the variation between these inventories.

The low correlation between neuroticism and harm avoidance and resultant heterogeneity may be the cause of the difference in results between the meta-analysis of NEO inventory studies and the meta-analysis of TCI/TPQ studies. It is unlikely that any inventory trait perfectly captures the exact psychological variation that associates with the 5-HTTLPR variant. Our results are best explained assuming that the true psychological variation associated with 5-HTTLPR is more closely approximated by neuroticism than by harm avoidance.

Overall, only 8 of the 23 included studies found a significant association between 5-HTTLPR and anxiety-related personality traits. It is likely that many of the non-replicating studies suffered from low power. Seventeen of the twenty-three studies had positive $\beta$ values, indicating higher anxiety-related personality trait scores for subjects with the 5-HTTLPR s allele. In addition, while eight studies found significant evidence for an association between the 5-HTTLPR s allele and higher trait scores, not a single study found an association between the alternate 5-HTTLPR 1 allele and higher trait scores, arguing against a chance distribution. For studies using NEO inventories, the weighted mean $\beta$ value across all studies was 1.06 , indicating that the addition of one s allele increased the trait score by 0.106 standard deviations. Although such a small effect is not unexpected for a complex trait, only the largest of these studies would have the power to detect this effect.

\section{ACKNOWLEDGMENTS}

We thank the authors of many of the cited studies for making available additional details of their published studies. We thank Scott Stoltenberg and Jeff Long for helpful discussions.

\section{REFERENCES}

Altshuler D, Hirschhorn JN, Klannemark M, et al. 2000. The common PPARgamma Pro12Ala polymorphism is associated with decreased risk of type 2 diabetes. Nat Genet 26:76-80.

Ball D, Hill L, Freeman B, et al. 1997. The serotonin transporter gene and peer-rated neuroticism. Neuroreport 8:1301-1304.

Costa PT Jr, McCrae RR. 1997. Stability and change in personality assessment: The revised NEO personality inventory in the year 2000. J Pers Assess 68:86-94. 
De Fruyt F, Van De Wiele L, Van Heerigan C. 2000. Cloninger's psychobiological model of temperament and character and the five-factor model of personality. Pers Individual Differences 29:441-452.

Deary IJ, Battersby S, Whiteman MC, Connor JM, Fowkes FG, Harmar A. 1999. Neuroticism and polymorphisms in the serotonin transporter gene. Psychol Med 29:735-739.

Du L, Bakish D, Hrdina PD. 2000. Gender differences in association between serotonin transporter gene polymorphism and personality traits. Psychiatr Genet 10:159-164.

Ebstein RP, Gritsenko I, Nemanov L, Frisch A, Osher Y, Belmaker RH. 1997. No association between the serotonin transporter gene regulatory region polymorphism and the tridimensional personality questionnaire (TPQ) temperament of harm avoidance. Mol Psychiatry 2:224-226.

Egger M, Davey Smith G, Schneider M, Minder C. 1997. Bias in metaanalysis detected by a simple, graphical test. BMJ 315:629-634.

Faraone SV, Doyle AE, Mick E, Biederman J. 2001. Meta-analysis of the association between the 7-repeat allele of the dopamine $\mathrm{D}(4)$ receptor gene and attention deficit hyperactivity disorder. Am J Psychiatry 158:1052-1057.

Flory JD, Manuck SB, Ferrell RE, Dent KM, Peters DG, Muldoon MF. 1999. Neuroticism is not associated with the serotonin transporter (5HTTLPR) polymorphism. Mol Psychiatry 4:93-96.

Gelernter J, Kranzler H, Coccaro EF, Siever LJ, New AS. 1998. Serotonin transporter protein gene polymorphism and personality measures in African American and European American subjects. Am J Psychiatry 155:1332-1338

Greenberg BD, Li Q, Lucas FR, et al. 2000. Association between the serotonin transporter promoter polymorphism and personality traits in a primarily female population sample. Am J Med Genet 96:202-216.

Gustavsson JP, Nothen MM, Jonsson EG, et al. 1999. No association between serotonin transporter gene polymorphisms and personality traits. Am J Med Genet 88:430-436.

Hamer DH, Greenberg BD, Sabol SZ, Murphy DL. 1999. Role of the serotonin transporter gene in temperament and character. J Personal Disord 13:312-327.

Hanna GL, Himle JA, Curtis GC, et al. 1998. Serotonin transporter and seasonal variation in blood serotonin in families with obsessivecompulsive disorder [see comments]. Neuropsychopharmacology 18: 102-111.

Heils A, Teufel A, Petri S, et al. 1995. Functional promoter and polyadenylation site mapping of the human serotonin (5-HT) transporter gene. J Neural Transm Gen Sect 102:247-254

Hirschhorn JN, Lohmueller K, Byrne E, Hirschhorn K. 2002. A comprehensive review of genetic association studies. Genet Med 4:45-61.

Jorm AF, Henderson AS, Jacomb PA, et al. 1998. An association study of a functional polymorphism of the serotonin transporter gene with personality and psychiatric symptoms. Mol Psychiatry 3:449-451.

Katsuragi S, Kunugi H, Sano A, et al. 1999. Association between serotonin transporter gene polymorphism and anxiety-related traits. Biol Psychiatry 45:368-370

Kluger AN, Siegfried Z, Ebstein RP. 2002. A meta-analysis of the association between DRD4 polymorphism and novelty seeking. Mol Psychiatry 7:712-717.

Kumakiri C, Kodama K, Shimizu E, et al. 1999. Study of the association between the serotonin transporter gene regulatory region polymorphism and personality traits in a Japanese population. Neurosci Lett 263: 205-207.
Lalovic A, Turecki G. 2002. Meta-analysis of the association between tryptophan hydroxylase and suicidal behavior. Am J Med Genet 114: 533-540.

Lesch KP, Bengel D, Heils A, et al. 1996. Association of anxiety-related traits with a polymorphism in the serotonin transporter gene regulatory region [see comments]. Science 274:1527-1531.

Loehlin JC. 1993. Nature, nurture, and conservatism in the Australian twin study. Behav Genet 23:287-290.

Lohmueller KE, Pearce CL, Pike M, Lander ES, Hirschhorn JN. 2003. Meta-analysis of genetic association studies supports a contribution of common variants to susceptibility to common disease. Nat Genet 33 : $177-182$.

Mazzanti CM, Lappalainen J, Long JC, et al. 1998. Role of the serotonin transporter promoter polymorphism in anxiety-related traits. Arch Gen Psychiatry 55:936-940.

Melke J, Landen M, Baghei F, et al. 2001. Serotonin transporter gene polymorphisms are associated with anxiety-related personality traits in women. Am J Med Genet 105:458-463.

Murakami F, Shimomura T, Kotani K, Ikawa S, Nanba E, Adachi K. 1999. Anxiety traits associated with a polymorphism in the serotonin transporter gene regulatory region in the Japanese. J Hum Genet 44 $15-17$.

Nakamura T, Muramatsu T, Ono Y, et al. 1997. Serotonin transporter gene regulatory region polymorphism and anxiety-related traits in the Japanese. Am J Med Genet 74:544-545.

Nakamura M, Ueno S, Sano A, Tanabe H. 2000. The human serotonin transporter gene linked polymorphism (5-HTTLPR) shows ten novel allelic variants. Mol Psychiatry 5:32-38.

Osher Y, Hamer D, Benjamin J. 2000. Association and linkage of anxietyrelated traits with a functional polymorphism of the serotonin transporter gene regulatory region in Israeli sibling pairs. Mol Psychiatry 5:216-219.

Ricketts MH, Hamer RM, Sage JI, Manowitz P, Feng F, Menza MA. 1998. Association of a serotonin transporter gene promoter polymorphism with harm avoidance behaviour in an elderly population. Psychiat Genet 8:41-44.

Samochowiec J, Rybakowski F, Czerski P, et al. 2001. Polymorphisms in the dopamine, serotonin, and norepinephrine transporter genes and their relationship to temperamental dimensions measured by the temperament and character inventory in healthy volunteers. Neuropsychobiology 43:248-253.

Sen S, Villafuerte S, Nesse R, Stoltenberg SF, Hopcian J, Gleiberman L, Weder A, Burmeister M. 2003. Serotonin transporter and GABA (A) alpha6 receptor variants are associated with neuroticism: Suggestion of an interaction. Biol Psychiatry (in press).

Stoltenberg SF, Twitchell GR, Hanna GL, et al. 2002. Serotonin transporter promoter polymorphism, peripheral indexes of serotonin function, and personality measures in families with alcoholism. Am J Med Genet 114:230-234.

Tsai SJ, Hong CJ, Cheng CY. 2002. Serotonin transporter genetic polymorphisms and harm avoidance in the Chinese. Psychiatr Genet 12:165-168

Umekage T, Tochigi M, Marui T, et al. 2003. Serotonin transporter-linked promoter region polymorphism and personality traits in a Japanese population. Neurosci Lett 337:13-16.

Zohar AH, Dina C, Rosolio N, Osher Y, Gritsenko I, Bachner-Melman R, Benjamin J, Belmaker RH, Ebstein RP. 2003. Tridimensional personality questionnaire trait of harm avoidance (anxiety proneness) is linked to a locus on chromosome 8p21. Am J Med Genet 117B(1):66-69. 